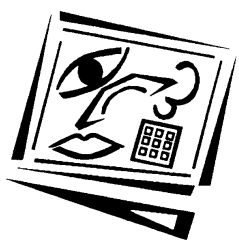

\title{
Harnessing distributed musical expertise through edublogging
}

\author{
Eddy K. M. Chong \\ Nanyang Technological University
}

\begin{abstract}
The pedagogical potential of edublogging — blogging used as an educational tool and strategy-in music teaching has been explored in two previous studies; a third exploration has now been conducted. Recognising the social and contextual dimensions of knowledge and of the learning process, I reflect on all three experiences from a distributed cognition perspective, as opposed to a traditional cognitivist one. First, the edublogging scenario in each case will be seen through the lens of distributed cognition in respect of the nature of its learning community and culture. Then, these instructional endeavours are evaluated against the distributed cognition ideals. The pedagogy discussed here leverages the potential of edublogging to draw on distributed musical expertise. Apart from being in line with the current trend in learning theories towards emphasising distributed cognition and community based learning, such a pedagogical strategy in part also offers a viable solution to the challenge of addressing an increasingly expanding curriculum, whether in music or other subjects, due to knowledge explosion and the pressures of globalisation.
\end{abstract}

\section{Introduction}

Educators have been urged to use the modern forms of technology in their teaching for almost half a century now, and, for the present increasingly networked society, the imperative to use ICT in our teaching is all the more stronger given its potential to, amongst other things, lend a supportive arm to collaborative learning (Hirsch, 2005b). The latter pedagogical advantage is particularly pertinent to the current trend towards more community based learning (e.g. Bereiter, 2002; Engeström, Engeström \& Suntio, 2002; Paavola \& Hakkarainen, 2005; Wenger, McDermott \& Synder, 2002), but equally, the use of ICT meets the increasingly pressing need of an emerging new generation of e-learners (Oblinger \& Oblinger, 2005; Conole, de Laate, Dillon \& Darby, 2006). It is against this backdrop that I shall focus on the use of blogging-originally a form of online diary (Blood, 2000) - to facilitate collaborative learning, and, specifically, the capitalisation of distributed expertise.

The pedagogical potential of edublogging-blogging used as an educational tool and strategy -in music teaching has been explored previously (Chong, 2006a, 2006b, 2007; Chong \& Soo, 2005a, 2005b, 2007; for other higher education uses, see for example Williams \& Jacobs, 2004). In this series of teacher-as-researcher investigations, edublogging has been found to have the potential to motivate learning as well as to foster higher order thinking and collaborative learning in music theory and analysis classes. As a further step to draw additional insights for the development of a pedagogy involving blogging, I re-examine these past experiences as well as a third one through the lens of distributed cognition. 


\section{Distributed cognition}

In post-Vygotskian educational psychology, the socio-anthropological work of Jean Lave and Etienne Wenger (Lave, 1988; Lave \& Wenger, 1991) has proven seminal in precipitating a more widespread and enhanced recognition of the social and contextual dimensions of knowledge and of the learning process. The premise here is that "'Cognition' observed in everyday practice is distributed - stretched over, not divided among-mind, body, activity and culturally organised settings (which include other actors)" (Lave, 1988, p.1; for a useful introduction to the literature on situated cognition, see Wilson \& Myers, 1999). Put differently, knowledge (or intelligence) is seen as residing not only "inside one's head", but also "in the social, physical and artifactual surroundings in which cognition and human activity take place" (Fischer, 2006). Against this understanding, a teaching approach premised on the traditional cognitivist view that knowledge is essentially "inside one's head" and that teaching primarily involves transmitting this knowledge from the teacher to the student appears educationally unsound and hence untenable.

Such an awareness in fact brings to the fore two related aspects about learning-the situative and the distributed nature of knowledge. Whilst not denying that knowledge is indeed embedded in and therefore contextualised by the learning environment and its attendant social-both interpersonal and cultural-milieu (Lave, 1988; Rogoff, 1999/1984), my interest here is in the distributive aspects. This idea of distributedness has been variously expressed as "stretched over" (Lave, 1988), "spread over" (Hewitt, 1998), "embodied" (Wilson, 2002) or the like. Whatever the expression, the basic recognition is of an indivisible system of cognition comprising "the mind, the setting, [the] activity, artefacts, signs, symbols, social processes and cultural factors", all interacting and interdependent (Hewitt, 1998, p. 77, after Greeno, 1997).

Not surprisingly, there are different scenarios of distributed knowledge. Educational researchers in the Vygotskian camp have long taken cognisance of the uneven distribution of knowledge and skills amongst teachers or parents and students in the classroom. On a different front, Gerhard Fischer, when capitalising on what he refers to as distributed intelligence to develop socio-technical systems for improving the human condition, speaks of distribution among people as well as distribution between human minds and artefacts (Fischer, 2006). From a more educational perspective, Salomon (1993) identifies two categories of distributed cognition: the first involves cognition distributed through some shared activity, the second involves a form of cognitive "off loading" onto certain tools (Salomon, 1993). Naturally, educators are most interested in the former type, though they are no less mindful of the latter. Now, whether the distribution amongst individuals is naturally occurring or engineered, the "asymmetry of knowledge" - or conversely the "symmetry of ignorance" (Fischer, 2004, after Rittel, 1984) - creates opportunities for collaboration, if not the motivation to do so as well. Aronson's jigsaw method of cooperative learning, for example, exemplifies well an artificial distribution of knowledge amongst learners to facilitate collaborative learning (Aronson, 1978, cited in Brown et al., 1993). In a less contrived manner, a knowledge building community is one that thrives on individual expertise that is shared to advance knowledge in a collective manner (Hewitt, 1998). Similarly, insofar as it incorporates collaborative learning such as collective problem solving, cognitive apprenticeship leverages the differing levels of knowledge and skills in individuals in the process of enculturation (Brown, Collins \& Duguid, 1989). In this article, I too am interested in the harnessing of distributed cognition-musical 
expertise in this case, and more naturally occurring at that-for collaborative learning, but one mediated by the technology of blogging.

\section{Blogging and collaborative learning: Three exploratory studies}

That blogging is seen as an ideal tool for fostering collaborative learning has been wellrecognised (for example, Weblogg-ed, 2006; EduBlog Insights, 2007): more than being just a personal online diary, blogging is fast becoming a great place (in cyberspace) to share and develop ideas. One American educator goes so far as to claim that weblogs (and wikis) "have the possibility of becoming perhaps the greatest education collaboration tools introduced since the World Wide Web became known in K-12 circles in the mid1990s" (Hirsch, 2005a). I shall therefore examine the extent to which my various edublogging strategies have harnessed blogging for collaborative learning involving the kinds of distributed cognition described above. Before we proceed, a brief summary of the edublogging explorations under review is necessary (Table 1).

Table 1: Summary of explorative studies

\begin{tabular}{|c|c|c|c|}
\hline & $\begin{array}{c}\text { First study } \\
\text { (Chong \& Soo, 2005a) }\end{array}$ & $\begin{array}{c}\text { Second study } \\
\text { (Chong \& Soo, 2005b) }\end{array}$ & Third (this) study \\
\hline $\begin{array}{l}\text { Technolog- } \\
\text { ical setup }\end{array}$ & $\begin{array}{l}\text { Student owned blogging } \\
\text { strategy }\end{array}$ & $\begin{array}{l}\text { roup owned blogging } \\
\text { rategy }\end{array}$ & $\begin{array}{l}\text { Student owned } \\
\text { blogging strategy }\end{array}$ \\
\hline Sample size & 6 individuals & 2 groups of 3 students each & 6 individuals \\
\hline \multirow[t]{3}{*}{\begin{tabular}{|l|} 
Blogging \\
tasks
\end{tabular}} & \multirow{3}{*}{$\begin{array}{l}\text { At least four out of a choice of } \\
\text { six for each student: } \\
\text { i. comparative analysis of given } \\
\text { musical excerpt and one } \\
\text { chosen by student } \\
\text { ii. short composing task + peer } \\
\quad \text { evaluation with justifications } \\
\text { iii. choice of two self reflection } \\
\text { tasks } \\
\text { iv. critical reading and response } \\
\text { v. mini-research task } \\
\text { vi. analysis of pop song }\end{array}$} & \multirow{2}{*}{$\begin{array}{l}\text { Free choice of group } \\
\text { project on pop songs, } \\
\text { musicals or film music; to } \\
\text { include: } \\
\text { i. background information } \\
\text { on song, composer } \\
\text { and/or singer } \\
\text { ii. song analysis } \\
\text { iii. compositional response }\end{array}$} & $\begin{array}{l}\text { First semester: Free } \\
\text { choice of music to } \\
\text { analyse (scope } \\
\text { similar to second } \\
\text { study) }\end{array}$ \\
\hline & & & \multirow{2}{*}{$\begin{array}{l}\text { Second semester: } \\
\text { Free choice of music } \\
\text { (now may include } \\
\text { non-western music) } \\
\text { based on student's } \\
\text { chosen investigative } \\
\text { focus }\end{array}$} \\
\hline & & $\begin{array}{l}\text { Final presentation mode: } \\
\text { information booklet or } \\
\text { website }\end{array}$ & \\
\hline
\end{tabular}

All three studies involved undergraduate, first year music theory and analysis courses, whose lecture component focused largely on the study of Western classical music. In the first study conducted during a one-semester course, six undergraduate students were each given individually owned blogs. My collaborator created the blogs for the students who then reset the password for individual ownership. As part of the course requirement, I stipulated six blog based assignments, of which the students chose to do four within a recommended schedule. In the second study, another six students in a similar course were involved, but this time they were grouped into threes and given a group owned blog to do their group projects. Also, the learning scope for the blogging tasks was now focused on one musical repertoire agreed upon by each group to complement their study of Western classical music. The group blog served as the platform for the collaborative investigation of the chosen music with teacher feedback given as comments on the blog entries. At the end of the semester, each group was required to consolidate their semester's work in the form of a hardcopy information booklet or a specially designed website.

Following these two studies, a third was conducted with a new group of six students in a similar course but over two semesters instead of one. Also, this time, the students 
created their own blog at blogspot.com (Blogger, 2008) as I reverted to an individually owned blogging strategy to give students a greater sense of ownership. In the first semester, the students shared and discussed on their own blog their analyses of three self chosen songs/pieces from the repertoires of popular music, musicals or film music. At the end of the semester, I gave them questions to prompt them to reflect on and consolidate their learning. In semester two, the same students continued to use their blogs to engage in further music analytical discussions. This time, they had to have a research focus/question when selecting music outside the Western classical repertoire to analyse.

Noting the presence of a non-classically trained pop musician and a very fine yangqin (Chinese zither played with a pair of light bamboo beaters ) player in this class, I specifically encouraged them to take advantage of their special musical background to broaden their analytical study of music. At the same time, I urged the class to see themselves (and their teacher) as members of a learning community, each having and at the same time developing different musical expertise in the understanding of different kinds of music. To this end, they would share via their individual blogs so as to learn from one another in this collective learning journey. At the end of the semester, I tailored test questions for individual students based on the pieces they have analysed to help them better consolidate and possibly extend their learning. Again, in the spirit of communal sharing, these individual sets of questions were made available for all to view; likewise, eventually, their answers (if they so wished) together with the teacher's comments.

\section{A community of learners: Its nature and culture}

The paradigmatic difference between teaching/learning premised on distributed cognition (that is, "distributive learning"), and the traditional, knowledge transmission model lies in the learning culture. Unlike the latter where learning is very much determined for the students, who are presumed to lack the knowledge (or skills) and hence expected to passively and often solitarily take in what is taught, with distributive learning, the class becomes a community of active learners. On the recognition that knowledge is/has been distributed-either naturally or by design-amongst members of the community (and not forgetting of course the social, symbolic and physical resources of the learning system or environment), students are expected to be able to collectively seek, construct and share knowledge. In other words, there is a strong social networking element in the learning process. In this regard, Barbara Rogoff's (Rogoff, 1999; Rogoff, Matusov \& White, 1996) conception of collective learning offers us a good point of departure in formulating a frame of reference to examine the extent to which the above edublogging ventures have capitalised on the synergy of interacting distributed expertise.

In Rogoff's participative model of learning (Rogoff et al., 1996), all members of the community are actively involved. They are very much given to take charge of their own learning rather than be passively following instructions. The teacher (or participating parents) may be present to give guidance and support, but the students essentially need to learn how to manage themselves as well as others in the process of the group inquiry: the whole inquiry process is ultimately structured by both the adults (teacher and participating parents) and the students. An important element in this collaboration is the "asymmetry of roles", meaning that individuals take on different roles so as to contribute complementarily to the shared endeavour. At the same time, 
the differing levels of expertise and experience create opportunities for legitimate peripheral participation-an important aspect in situated learning (Lave \& Wenger, 1991). Ideally, the class should be fundamentally and coherently structured as a cooperative system as opposed to one which merely incorporates some collaborative learning in a piecemeal or isolated manner. In the resultant learning culture, everyone learns how to learn and share.

Following Rogoff et al. (1996), we may identify the following ideals founded on the recognition of distributed cognition/intelligence:

i. the asymmetry of knowledge, seen as advantageous, is capitalised in the learning setup;

ii. the learning process involves active participation among the participants, this may include collaborative work, peer teaching, cognitive apprenticeship (Brown et al., 1989), or even peripheral participation (Lave \& Wenger, 1991);

iii. the learners take ownership of their learning and not only manage their own learning but also fellow inquirers'; in this connection, the learners "must take charge of high level process for knowledge advancement" (Hewitt, 1998, p. 81), as a result, the learning paths are collectively defined and structured as opposed to being dictated by the teacher;

iv. this collaborative system is the primary mode of instruction and learning, as opposed to being incorporated on an ad hoc piecemeal fashion.

In all of these, the teacher plays the role of planning and setting up the learning environment and then facilitating the whole process through modeling and coaching, amongst other things (Chong, 2006a). But researchers have also articulated a higher ideal in this regard: that the teacher should work towards "fading" (Brown et al., 1989) or "self elimination" (Rittel, 1984) so that learners eventually take full control of their learning. We shall return to this point towards the end of this article.

Now, to better understand the nature of the collaboration involved, it is useful to draw upon the distinction between a community of practice (CoP) (Wenger, 1998) and a community of interest (CoI) (Fischer, 2001, 2005b). To be clear, this is not to say that a class of students is a CoP or CoI (again, I shall address this more fully later); rather, I am appropriating this distinction for my evaluative purposes. In a CoP, participants come with the same domain knowledge, whereas in a CoI, they come with different conceptual knowledge systems and skills. Obviously, a common ground in the form of a shared practice and understanding would greatly facilitate collaboration. This is therefore a pertinent element in distributive learning.

\section{Blogging and distributed expertise}

Next, let us clarify the role of blogging in collaborative and, more specifically, distributive learning. Educators are well aware that technology is no more than a tool. As one researcher puts it, "Technologies popular for casual uses do not make the transition to being learning tools, without a lot of effort on the part of teachers" (Lewis, 2005); blogging may have "the capacity to stimulate today's technology savvy learners" (Metro, 2004), but it does not automatically facilitate collaborative learning: the teacher's facilitation is critical, including establishing and maintaining the motivational climate of the class (Chong, 2006b; similar lessons involving the use of wikis may be inferred from Choy \& $\mathrm{Ng}$, 2007). 
Apropos the potential of technology to harness distributed expertise, Hewitt and Scardamalia (1998) have pointed out that:

i. technology (read: blogging) can provide greater access to distributed expertise, overcoming "the logistical limitations associated with large group, face to face discourse" (p. 83)

ii. open access to the student created artifacts (in our case, blog postings) turns the latter into "intellectual resource for the entire classroom community", which "can be subsequently used as a foundation for other, more advanced artefacts" (p. 83).

At the same time, we may add that

iii. once these artifacts are available, the comment function on blogs allow members of the community (including the teacher) to provide feedback-what Fischer values as "back talk" or the "critiquing" element (Fischer, 2005b).

In other words, blogs serve as a means to externalise knowledge, the product of which is then stored for sharing and getting responses. Needless to say, the communication facilitated by blogging extends beyond the classroom (Chong \& Soo, 2005a, 2007). In a word, blogging can be a powerful collaborative tool that helps facilitate rich interactions to create a dynamic community of learners with different expertise. Indeed, the learning culture here typifies one that is fostered by the social software of what some have begun to refer to as Web 2.0 (O'Reilly, 2005)—a purportedly "second generation" of web services that tip the "read-write" scale towards the more active "write" functions.

\section{Distributive learning compared}

Let us first compare the nature of our three learning communities under examination vis-à-vis the CoP/CoI distinction. On the face of it, it would seem that our three communities in question in one respect resemble a homogeneous $\mathrm{CoP}$, one whose practice is delineated by the disciplinary boundary of Western music theory. There was a common ground insofar as the students were involved in learning to understand Western music; in fact, in the first study, all the students were classically trained musicians. In the second study, with the project placing more emphasis on popular music, a secondary musical interest and expertise in at least one of the students had emerged even though the students' musical background was otherwise similar to that of the first group. With the third study, the presence of a non-classically trained pop musician and a yangqin player brought forth a more marked degree of heterogeneity. Given that there are important differences in terms of musical mindset and musical practice in these two musical traditions, in contrast with Western classical (and the students having been strongly urged to draw upon their differing musical backgrounds for their projects), the community certainly had more of the heterogeneity characteristic of a CoI, the two students in question being taken as representative members of their respective musical communities. The common interest (in Fischer's sense) then was in collectively understanding music across different traditions (read: communities) whilst mastering and applying certain basic music analytical skills. To wit, the diversity of this third group has enabled the learning community, originally very much a CoP, to behave more like a CoI whereby different knowledge systems interacted. 
Apart from the knowledge base aspect, the kind of "collaboration" in the last study was also different from the earlier two (and certainly very different from the cases discussed by Fischer). In the first study, collaborative learning came in the form of peer comments and it was more the differing levels of expertise within more or less the same knowledge domain that was engaged. In the second study, the group work element entailed more collaborative work whereby, even though each member initially focused on analysing their own chosen songs within the scope of the group's agreed upon repertoire, they had to collate and consolidate their musical findings, albeit only towards the end of the semester. The third study had the group work element removed, making it seem like a return to the first scenario, but in at least one significant respect it was different. In the second semester, after the first semester initiation into blogging, the students were urged to think of themselves as working towards becoming experts on their individually chosen topic; the class was to be viewed as a community of learners tapping into one another's expertise and investigative findings. The group project then was a collective exploration of music across cultures, with blogging serving as the means to facilitate the sharing of this knowledge.

In fact, the collaboration, taken in a broader sense, went beyond the class. Given the affordances of the Internet, an ex-student who had participated in the first study, on my invitation, contributed to the blog discussion of the third study. As the facilitator, I had also personally invited two of my colleagues whose musical expertise complements mine to visit the students' blogs in the third study and contribute to the discussion if they like, so that (in Hewitt and Scardamalia's terms) "the student created artefacts" can lead to "more advanced artefacts". On the students' end, it was certainly obvious that a number of them took advantage of resources on the web, including at least one academic paper from a mainland Chinese music conservatory professor's website. I myself had also on occasions pointed students to appropriate Wikipedia articles and even to one group website from the second study for additional information. In distributed cognition parlance, these constitute access to "materially distributed cognition" (Hewitt \& Scardamalia, 1998)—knowledge distributed across learning artefacts, in this case, the repository of knowledge on the web. In one sense, this is tantamount to "roping in" other communities of expertise, albeit largely as passive contributors to the students' learning. Of course, the students had not eschewed the more conventional mode of accessing expertise, be it reading printed materials, consulting friends or interviewing practitioners:

Student 1: I chose to look at jazz .... I had some difficulties as jazz music had many elements I was unfamiliar with. After referring to books on jazz, I was able to understand the basic elements found in Jazz music and the different styles.... Through the feedback of my friends and tutor, I was able to get a better understanding ... [italics added]

Student 2: Basically, I looked at three of their more famous songs, and had a little chat with Mister Dino, front man of Force Vomit, to gather some insights that could back up my findings [italics added].

Admittedly, the extent to which that knowledge gained is shared depended much on the individual student's reportage, unlike the web accessed information which can be viewed first hand by any one interested. But whichever the mode of access to distributed knowledge and the extent of knowledge shared, of the three studies conducted, this latest group of edubloggers reached out farthest beyond the class in 
their blog facilitated collaborative learning! Figure 1 diagrams the flow of knowledge within this larger networked community.

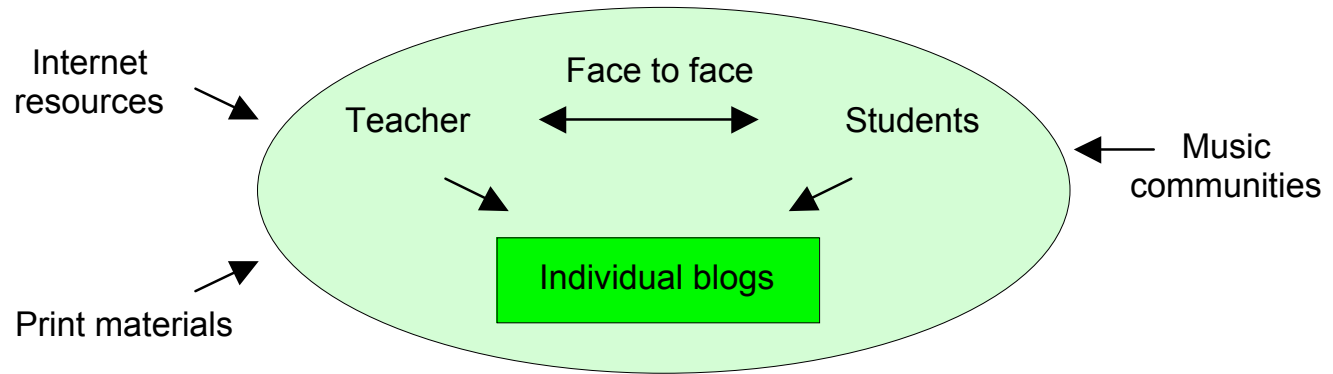

Figure 1: Flow of distributed expertise or

knowledge within the class and from without

\section{Peripheral participation and common ground}

From the above discussion, it may appear that, across the three studies, there was a move towards more of a CoI scenario. In one sense, this is true: insofar as there was one representative each from two additional music communities, the class in the third study had become "a community of communities", or more specifically "a community of representatives of communities" (Brown et al., 1991; Fischer, 2001). However, it would be misguided to think that peripheral participation-a feature more characteristic of a $\mathrm{CoP}-$ was absent. As it is, Fischer has noted that a community can exhibit attributes of both kinds of communities (Fischer, 2005a). Perhaps, peripheral participation played a much less significant role in Fischer's CoPs given that his representatives were experts in their fields, but our students here were by no means experts in their field(s) - not yet-and certainly not so in the primary knowledge domain of this course. Hence, whilst they were benefiting from a good range of expertise brought in via the different modes as summarised in Figure 1, they were at the same time mastering their basics, as it were. The collaborative setting therefore allowed for peripheral participation. One less active blogger in the third study reflected this at some length at the end of the second semester:

No doubt that my postings are much easier as compared to my other peers, ...it allows me to learn at a zone where I am comfortable with. Within this comfort zone, I can explore all the features of the songs at my own time and pace. Together with other peers and facilitator's comments, it enhances my analyses and improves my knowledge of the piece. Some other peers are able to see musical techniques in the pieces that I do not see. I constantly learn from them and sometimes bring in some [of] my own point of views [sic] ... [italics added]

I believe the novice status expressed here is not restricted to the primary knowledge domain: I'm sure some of the students were learning, on the community's periphery as it were, from the pop musician student about agogo music of the 1960s and surf punk of the 1970s; likewise about Chinese traditional music from the yangqin student. The lack of response at times to these latter two students' postings might well have been an indication of "lurking", a common cyberspace behaviour when individuals are not ready for more active participation (Nonnecke \& Preece, 2001). While none of the other students explicitly articulated this kind of peripheral learning, their blog comments that reflected some fascination over unfamiliar subjects and their request for 
clarification or additional information perhaps offer some circumstantial evidence for the symmetry of ignorance present within the class.

Focusing on the CoI aspects, it is easily apparent that the diversity of musical background was very much a boon to the class. Whilst in the first two studies, the learning only went as far as lateral application of concepts and analytical skills pertaining to classical music to music outside this repertoire, in the third study concepts extraneous to classical music were brought in, broadening the students' musical knowledge and understanding. For example, the mention of "power chords" in rock music pointed to an aesthetic view on open fifth chords very different from the classical musician; the idea of palm muting added an often neglected dimension to the understanding of music, namely, the noise element. In the analysis of musical structures, discussion of pop songs introduced such terms as riff, pre-chorus and outro on the one hand and turnaround on the other, suggesting that popular music can have their own structural elements somewhat distinct from their classical counterparts. In the discussion by the yangqin student, Chinese operatic elements were invoked to shed light on the yangqin concerto she was investigating. In all these cases, the limitations of the knowledge system of one community-namely, that of the classical musician-inevitably showed up more than once: a common ground was clearly needed to relate the different terminological and conceptual systems invoked (Fischer, 2005a). In such cases, I stepped in when needed to help establish a new level of common understanding by relating the new knowledge from a different musical tradition to what was formally taught in the lecture. In this way, the collective understanding of music achieved was broadened and enriched.

\section{Fallen short of ideals?}

Vis-à-vis the ideals drawn from Rogoff et al. (1996), we may observe that the students were given the chance to take ownership of their learning and strike out their own exploratory paths. But, as noted above, they were not always sufficiently competent to proceed on this journey without the help of a teacher. The idea of self directed learning in a community of learners was very novel to them; there was certainly a tendency to look to the teacher for answers or directions. And so, as evidenced in their blog postings (and end of term assessment in the third study), they only managed their own learning to varying degrees of success. Apropos the ideal of students managing their fellow students in the process of collaborative learning, the nature of the group work in the third study did not specifically call for such engagements. The second study, in comparison, allowed for more such opportunities; but, regrettably, this element in the group collaboration was not particularly highlighted or fostered. Needless to say, the first study was much like the third in this regard.

In another respect, we have also fallen short of ideals, at least at first glance. Fischer aims even higher than Rogoff and her associates. For him, a teacher playing the role of "a coordinator, facilitator, and coach" does not go far enough, he envisions collaborative knowledge construction driven by a symmetry of ignorance whereby no participant takes the role of a teacher. Instead, as articulate learners, all members of the community engage in largely peer to peer learning and take full control of the learning process, one which is facilitated by externalised ideas, concepts and goals ("objects to think with") (Fischer, 2004). But such an ideal would perhaps only be more possible with an adult community of practice, which is what Fischer, and Rittel (1984) for that matter, are dealing with. In a school situation, we need to accept that a class 
community does not have the same level of expertise, maturity and experience to achieve total self directed learning. The reservation expressed by one student from the second study over the open ended nature of the blog based learning is indirectly indicative and perhaps representative:

As no earmarked topics or content was tagged to the completion of this blogging

[group] project, it is difficult to ascertain how much actual 'learning' has taken place...

(Lim, 2006)

Not surprisingly, Rogoff and her associates have no qualms claiming that "it is consistent within the community of learners model for adults under some circumstances to provide strong leadership or extensive explanations to assist the group" (Rogoff et al., 1996). My edublogging experiences thus far would clearly support such a compromise (if one wishes to see it as such) (Chong, 2006a); but elsewhere, more generally, there is certainly much concurrence in the teaching community involved in the use of ICT on the teacher's critical role (see for example Steketee, 2006; Hong, 2008).

Finally, it may be admitted, these edublogging attempts have not met even the ideals set by Rogoff and her associates. In all instances, the blogging component formed only one part of the course. As implied above, this blog based learning was very much conceived to complement and supplement the taught component of the course. In other words, the collaborative system was far from being the primary mode of instruction and learning. To achieve this ideal, a radical overhaul of the course would be necessary, one that perhaps should be done only with better understanding of this new teaching/learning paradigm.

\section{Closing remarks}

In drawing upon the theoretical perspectives premised on situated learning and distributed cognition to evaluate my past edublogging endeavours, I have gone at some length to spell out the nature of the learning community and identify some attendant pedagogical ideals. Having evaluated the varying levels of success against these criteria, it bears reiterating that, for edublogging to succeed, we cannot merely rely on the technology itself: we need to, in Fischer's words, "co-evolve the social practice" (Fischer, 2006). In Fischer's case, it was to co-design both the social and technical systems (Fischer, 2005a); in our pedagogical context, it means that besides setting up the learning environment (including the creating of the blogs) and designing the blog assignments, we must not overlook the critical need to first initiate the students into this new mode of learning, then facilitate the process thereafter in an appropriate way (Chong, 2006a, 2006b, 2007; see also Hong, 2008). To say this is to concur with dePaula, Fischer \& Ostwald (2001) that the real challenge in implementing collaborative technology (read: edublogging) is more a cultural than a technical one: the learners" "behaviors, goals, values, and attitudes toward education" - that is, "the culture of education" (Bruner, 1996) — need to be changed for blog based collaboration (and indeed any new educational technology for that matter) to succeed in educational settings.

This challenge is worth taking up. One of the great advantages of this teaching/learning strategy is that it opens up the curriculum boundaries without necessarily eschewing a certain core. To use the case of music teaching as an illustration, in our increasingly globalised society with classes increasingly comprising 
migrant students, the blog based approaches discussed above offer a means to strike a balance between teaching core concepts and skills on the one hand, and bringing in topics previously excluded from the mainstream curriculum on the other; the latter thereby catering to the disparate musical preferences of students. At the same time, unlike in traditional approaches, differences in knowledge domain and level are not seen as problematic but turned into a pedagogical advantage. Besides its potential to enrich and broaden learning, the strategy allows us to develop independence in the students' music learning, and an active one at that. The ideal, of course, is to transform the students from being passive consumers of knowledge to active co-producers, from being an outsider to being part of a larger learning community-and one that is networked beyond the classroom. For the teacher, success in this regard would have been gratifying enough, but more than that, the unpredictability of the students' learning directions and outcomes can itself be most exciting and rejuvenating for those who have been in the teaching profession for many years!

\section{Acknowledgements}

An earlier version of this paper was presented at the conference Redesigning Pedagogy: Culture, Knowledge and Understanding, held at the National Institute of Education, Nanyang Technological University, on 28-30 May 2007 (Chong, 2007). I am grateful to Dr Ashley Tan for his helpful comments on the conference version of this paper.

\section{References}

Bereiter, C. (2002). Education and mind in the knowledge age. Hillsdale, NJ: Erlbaum.

Blogger (2008). Create your Blog Now -- FREE. https: / www.blogger.com/start

Blood, R. (2000). Weblogs: A history and perspective. Rebecca's Pocket. [viewed 6 Jul 2007]. http: / / www.rebeccablood.net/essays / weblog_history.html

Brown, A. L., Ash, D., Rutherford, M., Nakagawa, K., Gordon, A. \& Campione, J. C. (1993). Distributed expertise in the classroom. In G. Salomon (Ed.), Distribution cognitions: Psychological and educational considerations (pp. 188-228). Cambridge: Cambridge University Press.

Brown, J. S. \& Duguid, P. (1991). Organizational learning and communities-of-practice: Toward a unified view of working, learning and innovation. Organization Science, 2(1), 40-57.

Brown, J. S., Collins, A. \& Duguid, P. (1989). Situated cognition and the culture of learning. Educational Researcher, 18, 32-42.

Bruner, J. (1996). The culture of education. Cambridge, MA: Harvard University Press.

Chong, E. K. M. (2006a). Blogging in music teaching: Engaged learning beyond classroom and disciplinary boundaries. Paper presented at the Educational Research Association of Singapore Conference, 29-31 May, Singapore.

Chong, E. K. M. (2006b). From blogging to self-regulated learning in music. Paper presented at the Asia Pacific Educational Research Association Conference, 28-30 Nov, Hong Kong. [verified 18 Jan 2008]. http:/ / www.edublog.net/astinus/mt/files/docs/apera\%20paper-chongeddy.pdf

Chong, E. K. M. (2007). Edublogging and distributed expertise in music teaching. Proceedings of Redesigning Pedagogy: Culture, Knowledge and Understanding Conference, Singapore, May. http: / / conference.nie.edu.sg/2007/ paper/ papers / COG199.pdf 
Chong, E. K. M. \& Soo, W. M. (2005a). Higher-order learning in music through blogs. Paper presented at the Redesigning Pedagogy Conference, 30 May - 1 June, Singapore.

Chong, E. K. M. \& Soo, W. M. (2005b). Integrative and collaborative music learning using blogs. Paper presented at the Association for Technology in Music Instruction and College Music Society joint-conference, 3-6 Nov, Quebec City.

Chong, E. K. M. \& Soo, W. M. (2007). Adaptive learning through blogging: A case study in music teaching. In C. Shegar \& R. A. Rahim (Eds.), Redesigning pedagogy: Voices of practitioners (pp. 15-31). Singapore: Pearson.

Choy, S. O. \& Ng, K. C. (2007). Implementing wiki software for supplementing online learning. Australasian Journal of Educational Technology, 23(2), 209-226. http: / / www.ascilite.org.au/ajet/ajet23/ choy.html

Conole, G., de Laate, M., Dillon, T., \& Darby, J. (2006). An in-depth case study of students' experiences of e-Learning--how is learning changing? In Who's Learning? Whose Technology? Proceedings ascilite Sydney 2006.

http:/ / www.ascilite.org.au/conferences / sydney06/proceeding/pdf_papers/p127.pdf

dePaula, R., Fischer, G. \& Ostwald, J. (2001). Courses as seeds: Expectations and realities. Paper presented at the European Conference on Computer-Supported Collaborative Learning (Euro-CSCL 2001), Maastricht, The Netherlands, March 22-24, 2001. [verified 7 Feb 2008] http:/ / 13d.cs.colorado.edu/ gerhard/ papers/ecscl2001.pdf

EduBlog Insights (2007). Archive for the ‘Pedagogy' category. [verified 7 Feb 2008] http: / / anne.teachesme.com/ category/pedagogy /

Engeström, Y., Engeström, R. \& Suntio, A. (2002). Can a school community learn to master its own future? An activity theoretical study of expansive learning among middle school teachers. In G. Wells \& G. Claxton (Eds), Learning for life in the 21st century. Oxford: Blackwell.

Fischer, G. (2001). Communities of interest: Learning through the interaction of multiple knowledge systems. Paper presented at the 24th Annual Information Systems Research Seminar in Scandinavia (IRIS'24), Ulvik, Norway. [verified 7 Feb 2008] http:/ / 13d.cs.colorado.edu/ gerhard/papers/iris24.pdf

Fischer, G. (2004). Social creativity: Bringing different points of view together. KBS Special Issues "CEC'99". [verified 7 Feb 2008] http:/ / 13d.cs.colorado.edu/ gerhard/papers/kbs2000.pdf

Fischer, G. (2005a). Beyond binary choices: Understanding and exploiting trade-offs to enhance creativity. In J. S. Gero, \& M.L. Maher (Eds.), Computational and cognitive models of creative design (pp. 71-92). Sydney: Key Centre of Design Computing and Cognition, University of Sydney. [verified 7 Feb 2008] http:/ / faculty.arch.usyd.edu.au/kcdc/books/hi05/index.html

Fischer, G. (2005b). From reflective practitioners to reflective communities. Paper presented at the HCI International Conference (HCII), Las Vegas. [verified 7 Feb 2008]

http: / / 13d.cs.colorado.edu/ gerhard / papers/ reflective-communities-hcii-2005.pdf

Fischer, G. (2006). Distributed intelligence: Extending the power of the unaided, individual human mind. Paper presented at the Advanced Visual Interfaces (AVI) Conference, Venice, May 23-26, 2006. [verified 7 Feb 2008]

http: / / 13d.cs.colorado.edu/ gerhard/ presentations/ slides-avi-final.pdf

Greeno, J. G. (1997). Response: On claims that answer the wrong questions. Educational Researcher, 26(1), 5-17.

Hewitt, J. \& Scardamalia, M. (1998). Design principles for distributed knowledge building processes. Educational Psychology Review, 10(1), 75-96. 
Hirsch, J. (2005a). The education blogosphere: Blogs and wikis. [viewed 10 Jun 2006, verified 7 Feb 2008]. http: / / www.aasa.org / publications / content.cfm?ItemNumber $=2824$

Hirsch, J. (2005b). Learning collaboratively with technology. The School Administrator, 62(7).

Hong, L. (2008). Blending online components into traditional instruction in pre-service teacher education: The good, the bad, and the ugly. International Journal for the Scholarship of Teaching and Learning, 2(1). [viewed 16 Jan 2008]. http:/ / www.georgiasouthern.edu/ijsotl/v2n1/articles/Lin/index.htm

Lave, J. (1988). Cognition in practice: Mind, mathematics and culture in everyday life. Cambridge: Cambridge University Press.

Lave, J. \& Wenger, E. (1991). Situated learning: Legitimate peripheral participation. Cambridge: Cambridge University Press.

Lewis, G. (2005). Can blogs be useful educational tools? [verified 7 Feb 2008]. http:/ / www2.warwick.ac.uk/services/cap/resources/pubs/forum/archive/issue30/blogs

Lim, Y. B. (2006). Unpublished student paper on the usefulness of blogging in music learning.

Metro, S. (2004). Engaging e-learners. [viewed 7 Feb 2006, verified 7 Feb 2008, abstract only]. http:/ / www.griffith.edu.au/text/conference/eagenda2004/content_na_participants_bios.html

Nonnecke, B. \& Preece, J. (2001). Why lurkers lurk. Paper presented at the AMCIS Conference, Boston MA, 3-5 August. [viewed 13 Jul 2007, verified 7 Feb 2008]. http:/ / www.cis.uoguelph.ca/ nonnecke/ research/whylurk.pdf

Oblinger, D., \& Oblinger, J. (Ed.). (2005). Educating the Net Generation. Boulder, CO: Educause. http:/ / www.educause.edu/ educatingthenetgen

O'Reilly, T. (2005). What is Web 2.0? [viewed 28 Sep 2007, verified 7 Feb 2008]. http:/ / www.oreilly.com/pub/a/oreilly/tim/news/2005/09/30/what-is-web-20.html

Paavola, S. \& Hakkarainen, K. (2005). The knowledge creation metaphor - An emergent epistemological approach to learning. Science E Education, 14, 535-557.

Rittel, H. (1984). Second-generation design methods. In N. Cross (Ed.), Developments in design methodology (pp. 317-327). New York: John Wiley \& Sons.

Rogoff, B. (1999). Introduction: Thinking and learning in social context. In B. Rogoff \& J. Lave (Eds.), Everyday cognition: Development in social context (pp. 1-8). Cambridge, MA: Harvard University Press.

Rogoff, B., Matusov, E. \& White, C. (1996). Models of teaching and learning: Participation in a community of learners. In D. R. Olson, \& Torrance, N. (Eds.), The handbook of education and human development (pp. 388-414). Oxford: Blackwell.

Salomon, G. (1993). No distribution without individuals' cognition: A dynamic interactional view. In G. Salomon (Ed.), Distributed cognitions (pp. 111-138). Cambridge: Cambridge University Press.

Steketee, C. (2006). Modelling ICT integration in teacher education courses using distributed cognition as a framework. Australasian Journal of Eudcational Technology, 22(1), 126-144. http: / / www.ascilite.org.au/ajet/ajet22/steketee.html

Weblogg-ed (2006). Why weblogs? [verified 7 Feb 2008\} http:/ / weblogg-ed.com/ why-weblogs /

Wenger, E. (1998). Communities of practice -- Learning, meaning, and identity. Cambridge: Cambridge University Press. 
Wenger, E., McDermott, R. \& Synder, W. M. (2002). Cultivating communities of practice. Boston: Harvard Business School Press.

Williams, J. B. \& Jacobs. J. (2004). Exploring the use of blogs as learning spaces in the higher education sector. Australasian Journal of Educational Technology, 20(2), 232-237. http:/ / www.ascilite.org.au/ajet/ajet20/williams.html

Wilson, B. \& Myers, K. M. (1999). Situated cognition in theoretical and practical context. In D. Jonanssen, \& S. Land (Eds.), Theoretical foundations of learning environments (pp. 57-88). Mahwah, NJ: Erlbaum.

Wilson, M. (2002). Six views of embodied cognition. Psychonomic Bulletin E Review, 9(4), 625-636. [verified 7 Feb 2008] http:/ / www.indiana.edu/ cogdev/labwork/WilsonSixViewsofEmbodiedCog.pdf

Eddy K. M. Chong, Assistant Professor, Visual and Performing Arts, National Institute of Education, Nanyang Technological University, Singapore 637616.

Email: eddy.chong@nie.edu.sg 